Guest Editorial, part of a Special Feature on Crossing Scales and Disciplines to Achieve Forest Sustainability

\title{
Crossing Scales and Disciplines to Achieve Forest Sustainability
}

\author{
$\underline{\text { Michael J. Papaik }}^{1}$, Brian Sturtevant $^{2}$, and Christian Messier $^{1}$
}

Key Words: decision support; ecosystem management; forest sustainability; interdisciplinary modeling; land planning; participatory modeling; scaling; sustainable forest management.

Forest land managers are faced with unprecedented global pressures to produce resources for human consumption (e.g., Liu and Diamond 2005), while still maintaining essential ecosystem services benefiting society at multiple spatial scales (Costanza et al. 1997). These global pressures alone present daunting challenges to sustainable forest management (SFM) worldwide (Lunnan et al. 2004, Essman et al. 2007), but they are occurring in the context of an unprecedented rate of climate change (Solomon et al. 2007) that is anticipated to have drastic effects on forest ecosystem productivity and function (Melillo et al. 1993, Dale et al. 2001, Garcia-Gonzalo et al. 2007). The rate and scale of these social, economic, and environmental changes facing forestry worldwide underscores an urgent need to understand their multiscale interactions and use that insight to guide SFM planning efforts into an uncertain future (Innes and Hickey 2006).

Traditional SFM, with its focus on stand-scale management, forest productivity, and system simplification, often leads to undesirable landscape conditions (Hunter 1990, Cissel et al. 1994, Bergeron et al. 1999) and increased vulnerability to disturbance (Holling and Meffe 1996, Haeussler and Kneeshaw 2003, Folke et al. 2004, Anderies et al. 2006). New approaches to resource management that focus on system resilience rather than resource flow have been argued as a more tenable framework for sustainability because they embrace change rather than work against it (Holling and Meffe 1996). Managing for system resilience requires an institutional paradigm shift away from system simplification to managing for system complexity at multiple scales (Holling and Meffe 1996). However, despite its intuitive appeal, land planners are reluctant to make the leap from planning for production to planning for resilience because system resilience is a moving target that requires understanding of complex social and ecological feedbacks (Anderies et al. 2006).

Although there has been a surge of simulation models developed or adapted to support the forest planning process and to clarify some of the uncertainties associated with sustainable resource management, most available models are constrained by persistent boundaries between scientific disciplines, and by the scale-specific processes for which they were created (Messier et al. 2003, Sturtevant et al. 2007). Further, strategic and broadscale forest planning efforts based on such models are often frustrated by complex interactions among ecological, social and economic processes, each operating at their own characteristic spatiotemporal scales. A more integrated and flexible modeling framework is required, one that guides the selection of which processes to model, defines the scales at which they are relevant, and carefully integrates them into a cohesive whole.

In this special feature we present several multidisciplinary projects that use a variety of approaches designed to meet sustainable forest landscape management objectives in a variety of forest ecosystems around the world. It weaves together two interacting themes: (1) interdisciplinary approaches for guiding sustainable forest landscape design, and (2) scaling issues underlying the integration of socioeconomic and ecological processes when modeling managed forest ecosystems. Case studies presented here range from tropical to boreal systems and provide examples of 
integrated approaches to understanding multiscaled human-forest interactions through various combinations of empirical study, cultural investigations, GIS, simulation modeling, and scenario analyses. Our goal was to synthesize insights from these different studies and systems to reveal general principles that can guide effective sustainable landscape design in any social, economic, and ecological setting where humans desire balance between forest resource use, ecological integrity, and quality of life.

Four studies incorporated novel analytical and interdisciplinary approaches to assess long-term impacts of human activities on forest resource sustainability. Pijanowski et al. (2007), developed a historical land change model and a groundwater flow model with ArcInfo GIS data for a western Michigan mixed land use (i.e., urban/suburban, agricultural, and forest) landscape to examine the impacts of past land use on current water quality. Their results show how past land use patterns are recognizable in the spatial signature of groundwater quality, suggesting that evaluating forest ecosystem services such as clean water may require a broad perspective in both time and space. Dale et al. (2008) integrated models from a suite of disciplines to understand how land use change affected legal standards of sustainability defined by US environmental law. The authors simulated the effects of land-cover changes on the spatial impacts of several environmental pollutants including nutrient export, ozone concentrations, noise, and habitat changes for two threatened and endangered species in five Georgia (USA) counties. By integrating environmental assessments across their different environmental dimensions, the authors gained a more holistic understanding of the consequences of land use policy on the quality of life in the region. Integrated modeling was essential to fully assess cumulative impacts, trade-offs among different environmental values, and relative sensitivity of those values to different land use change scenarios. McComb et al. (2007) forecasted the effects of current forest management policies on future habitat quality for three vertebrate species. Their model scenarios illustrate how the mixture of private and government land ownership, combined with the inertia of forest ecosystems, affects longterm spatial pattern of forests and its consequences for habitat sustainability of indicator species. Finally, Morgan et al. (2008) used "real options," a risk assessment technique adapted from economics, to evaluate trade-offs between economic return from harvest and relative risk of extirpating woodland caribou (Rangifer tarandus caribou), a vitally important local resource, given uncertainty in habitat availability associated with fire disturbance in central Labrador. Combined, these four studies illustrate how modeling initiatives can blend the strengths of different disciplines and create new insights into human-ecosystem interactions both affecting and defining forest sustainability.

Three papers explored different cultural and ecological dimensions of indigenous land use practices that provide insights into potential SFM practices and values of modern society at broader scales. In a study that addressed both cross-cultural and cross-scale challenges, (O'Flaherty et al. 2008) highlights a central dilemma, i.e., how to balance and integrate the local needs and perceptions of indigenous communities, or by proxy, any local community, with the broader goals of a province or nation within which the indigenous organization is embedded. Using woodland caribou conservation as a value that crosses human cultures in northern Ontario, Canada, the authors illustrate how conflicts can arise even between parties with common conservation agendas if care is not taken in establishing a cultural context. First Nations stakeholders with a strong cultural and local connection to their land encouraged a global perspective on conservation at their scale of interest, i.e., on their land, whereas traditional environmentalists and provincial government stakeholders with a province-wide scale conservation agenda encouraged partitioning the landscape at the scale of interest of the First Nations stakeholders. Thus scale has a cultural as well as physical context that must be accounted for when managing for sustainability.

Natcher et al. (2007) used a mixture of GIS and ethno-ecological methods to contrast different cultural burning practices applied by two neighboring Athabaskan ethnic groups of northern Alaska. Their study showed that local ecosystem attributes constrained the application of fire differently for the two groups and led to divergent but equally sustainable cultural land use practices and forest dynamics. Roy Chowdhury (2007) investigated contemporary rural development patterns and subsequent reforestation and biodiversity of secondary forests in Yucatan, Mexico, a hot spot for tropical biodiversity and landuse conversion. The author used a combination of household surveys, remote sensing, and field studies to understand how household-scale socioeconomics 
interacted with higher-level land-use incentive programs to affect reforestation patterns and ultimately tree biodiversity in the region. These two studies show that both economic and ecological drivers can have significant influence over local land use practices shaping forest dynamics. However the ecological drivers reported by Natcher et al. were internal to the ecosystem, providing strong feedbacks affecting the sustainability of land management choices to which the local populations crafted their individual responses. In contrast the economic incentive programs examined by Roy Chowdhury (2007) were external to the local ecosystem, and therefore require research and monitoring as feedbacks to evaluate the relative sustainability of different land use policies.

Modern society, with its global economy and burgeoning human population, now overwhelms local ecological feedback mechanisms that encourage sustainable use of natural resources. Balance between internal and external drivers of land management is therefore essential for longterm sustainability of forest ecosystem services affecting multiple scales of human society. O'Flaherty et al. (2008) approached the problem from the perspective of human culture to illustrate how different scales of perception, experience, and ecological understanding compound cultural differences and impede the planning process if they are not incorporated into it. Sturtevant et al. (2007) offered a "toolkit" modeling approach to balance internal and external information, understanding, and values used to build models that forecast landscape response to human and ecosystem agents of change in managed forests. Their approach crossed social, ecological, and economic domains and spanned different scales relevant to key human and ecological processes affecting SFM. A toolkit of accessible models and model-building tools became the vehicle for exchanging internal and external knowledge when embedded within a hierarchical participatory modeling framework. The risk analysis work of Morgan et al. (2008) was a component of this larger initiative. Hence these two insight papers offer strategies to reconcile local needs and system understanding with broader-scale values and scientific insights, building upon the adaptive management framework suggested three decades ago (Holling 1978).

We see three general principles that could benefit SFM emerging from these studies. First, forested ecosystems present a special challenge for sustainability, because long-term processes associated with tree growth and forest development typically translate into high levels of system inertia such that decisions made today will generally have long-lasting influence on future forest conditions (Spies et al. 1994). System inertia is evident in multiple indicators reflecting different ecosystem services, including wildlife habitat (McComb et al. 2007, Dale et al. 2008, Morgan et al. 2008), biodiversity (Roy Chowdhury 2007), water quality (Pijanowski et al. 2007), and air quality (Dale et al. 2008). By contrast, both societal values (Swanson 2004) and drivers affecting land use change (Roy Chowdhury 2007) often change more rapidly, i.e., at temporal scales from years to decades rather than centuries. Effective SFM must therefore address and reconcile the mismatch in temporal scale between human and ecological processes affecting forest change.

The second insight follows from how modern human interactions with ecosystems are now fundamentally multiscaled in both space and time and affected by local, regional, national, and international values and needs. Successful SFM must simultaneously consider local and broaderscale perspectives, both in ecosystem processes and human needs. These papers illustrate this in three ways. First, human manipulation of ecosystems driven by local needs and shaped by constraints imposed by the environment, e.g., burning, can result in a simple recipe for locally determined sustainability (Natcher et al. 2007). Second, broader perspectives offered by synergistic studies provide insights into long-term consequences across several scales (e.g., McComb et al. 2007, Dale et al. 2008). Third, by considering only one of these two perspectives, conflict can ensue in the application of SFM even when all parties are sold on the concept (O'Flaherty et al. 2008).

The third general insight follows from this multiple scale perspective. There is a growing recognition that the chances for successful SFM can be drastically improved by empowering local stakeholders, i.e., those most directly affected by the manipulation of their ecosystem, to weigh in on forest management decisions (Sturtevant et al. 2007, McComb et al. 2007, Dale et al. 2008, O'Flaherty et al. 2008). Such empowerment requires understanding not only of cultural differences between local communities and broader-scale society, but also the scales of perception and differences in the depth and character of knowledge 
associated with stakeholders at these different social levels. But, whereas local empowerment is a necessary condition for successful SFM, it is not sufficient because scientific knowledge and other expertise required to effectively guide SFM is often found outside of local communities (Sturtevant et al. 2007). Because modern SFM is heavily affected by broader-scaled social values and needs, SFM planning must somehow reconcile the disparate scales of human and ecological drivers of change, and remain adaptable to changing conditions and circumstance.

Taken as a whole the papers in this special feature suggest that integrative modeling can facilitate SFM planning for ecosystem resiliency in a way that is adaptable to the inevitable uncertainties of the future. However, effective SFM modeling support requires, at a minimum, a cross section of insights from landscape and ecosystem ecology, ecological economics, and social science, combined with a management process that integrates scientific models and participatory planning. Although resource management is one of the primary objectives of these studies, all are heading toward a more comprehensive analysis and understanding of the effect of human activities on ecosystem services. The Canadian Boreal Forest Initiative has estimated that noneconomic valuation of the boreal forest is 2.5 times the current production-based economic value of the ecosystem (www.borealcanada.ca/doc uments/Boreal Wealth Report Nov 2005.pdf).

Thus, in addition to the ecological benefits cited earlier, there is considerable economic potential in resilience-based SFM.

The approaches explored in this special feature are still just a beginning as we continue to advance our knowledge and our ability to minimize our impact on an increasingly vulnerable global ecosystem. Meeting the multiple resource management needs of the 21 st century will be a significant challenge to us culturally as well as scientifically. We will succeed only if SFM can find ways to operate within a global context and yet remain sensitive to local ecological and social conditions.

Responses to this article can be read online at: http://www.ecologyandsociety.org/voll3/iss 1/art30/responses/

\section{Acknowledgments:}

The special feature follows a symposium under the same title that took place at the 2006 annual meeting of the US Regional Chapter of the International Association for Landscape Ecology in San Diego, $C A$. The work to support development of the symposium and this special feature was funded through the Sustainable Forest Management Network of Canada, the Centre d'étude de la forêt at the University of Quebec at Montreal, and the US National Fire Plan. We dedicate this special feature in kind memory of Neal Simon, a great friend and colleague, who was one of the original organizers of the symposium and an editor for this special feature before his untimely death.

\section{LITERATURE CITED}

Anderies, J. M., B. H. Walker, and A. P. Kinzig. 2006. Fifteen weddings and a funeral. Ecology and Society 11(1):21. [online] URL: http://www.ecolog yandsociety.org/vol11/iss1/art21/.

Costanza R, R. dArge, R. deGroot, S. Farber, M. Grasso, B. Hannon, K. Limburg, S. Naeem, R. V. ONeill, J. Paruelo, R. G. Raskin, P. Sutton, and M. vandenBelt. 1997. The value of the world's ecosystem services and natural capital. Nature $\mathbf{3 8 7}$ (6630):253-260.

Dale, V. H., F. Akhtar, M. Aldridge, L. Baskaran, M. Berry, M. Browne, M. Chang, R. Efroymson, C. Garten, Jr., E. Lingerfelt, and C. Stewart. 2008. Modeling the effects of land use on the quality of water, air, noise, and habitat for a five-county region in Georgia. Ecology and Society 13(1): 10. [online] URL: http://www.ecologyandsociety.org/vol13/ iss1/art10/.

Dale, V., L. Joyce, S. McNulty, R. Neilson, M. Ayres, M. Flannigan, P.Hanson, L. Irland, A. Lugo, C. Peterson, D. Simberloff, F. Swanson, B. Stocks, and B. Wotton. 2001. Climate change and forest disturbances. BioScience 51:723-734.

Essman H. F., G. Andrian, D. Pattenella, and P. Vantomme. 2007. Influence of globalization on forests and forestry. Allgemeine Forst Und 
Jagdzeitung 178:59-68.

Holling, C. S., editor. 1978. Adaptive environmental assessment and management. Wiley, Chichester, UK.

Holling, C. S., and G. K. Meffe. 1996. Command and control and the pathology of natural-resource management. Conservation Biology 10:328-337.

Innes J. L., and G. M. Hickey. 2006. The importance of climate change when considering the role of forests in the alleviation of poverty. International Forestry Review 8:406-416.

Folke, C., S. R. Carpenter, B. H. Walker, M. Scheffer, T. Elmqvist, L. H. Gunderson, and C. S. Holling. 2004. Regime shifts, resilience, and biodiversity in ecosystem management. Annual Review of Ecology, Evolution and Systematics 35:557-581.

Garcia-Gonzalo, J., H. Peltola, E. BricenoElizondo, and S. Kellomaki. 2007. Ecological modelling 209(2-4):220-234.

Haeussler, S., and D. Kneeshaw. 2003. Comparing forest management to natural processes. Chapter 9 in Towards sustainable management of the boreal forest. P. Burton, C. Messier, D. W. Smith, and W. L. Adamowicz, editors. National Research Council of Canada, Ottawa, Ontario, Canada.

Larkin, P. A. 1977. Epitaph for the concept of maximum sustained yield. Transactions of the American Fisheries Society 106(1):1-11.

Liu, J, and J. Diamond. 2005. China's environment in a globalizing world. Nature 435:1179-1186.

Lunnan A., M. Nylinder, and M. Karkkainen. 2004. Forestry and economic development: research challenges and possibilities for future interdisciplinary research in technology and economics. Scandinavian Journal of Forest Research 19:97-104.

McComb, B. C., T. A. Spies, and K. A. Olsen. 2007. Sustaining biodiversity in the Oregon Coast Range: potential effects of forest policies in a multiownership province. Ecology and Society 12(2):29. [online] URL: http://www.ecologyandsociety.org/voll2/ iss $2 / \operatorname{art} 29 /$.
Melillo, J. M., A. D. Mcquire, D. W. Kicklighter, B. Moore, C. J. Vorosmarty, and A. L. Schloss. 1993. Global climate-change and terrestrial net primary productivity. Nature 363:(6426):234-240.

Messier, C., M-J. Fortin, F. Schmiegelow, F. Doyon, S. G. Cumming, J. P. Kimmins, B. Seely, C. Welham, and J. Nelson. 2003. Modelling tools to assess the sustainability of forest management scenarios. Chapter 14 in P. Burton, C. Messier, D. W. Smith, and W. L. Adamowicz, editors. Towards sustainable management of the boreal forest. National Research Council of Canada, Ottawa, Ontario, Canada.

Morgan, D. G., S. Ben Abdallah, and P. Lasserre. 2007. Real options approach to forest management decision making to protect caribou under the threat of extinction. Ecology and Society 13(1):27. [online] URL: http://www.ecologyandsociety.org/vol13/ iss $1 / \operatorname{art} 27 /$.

Natcher, D. C., M. Calef, O. Huntington, S. Trainor, H. P. Huntington, L. DeWilde, S. Rupp, and F. Stuart Chapin III. 2007. Factors contributing to the cultural and spatial variability of landscape burning by native peoples of Interior Alaska. Ecology and Society 12(1):7. [online] URL: http://www.ecologyandsociety.org/vol12/iss1/art7/

O'Flaherty, R. M., I. J. Davidson-Hunt, and M. Manseau. 2008. Indigenous knowledge and values in planning for sustainable forestry: Pikangikum First Nation and the Whitefeather Forest Initiative. Ecology and Society 13(1): 6. [online] URL: http:// www.ecologyandsociety.org/vol13/iss1/art6/.

Pijanowski, B., D. K. Ray, A. D. Kendall, J. M. Duckles, and D. W. Hyndman. 2007. Using backcast land-use change and groundwater traveltime models to generate land-use legacy maps for watershed management. Ecology and Society 12 (2):25.[online] URL: http://www.ecologyandsociety. org/vol12/iss2/art25/.

Roy Chowdhury, R. 2007. Household land management and biodiversity: secondary succession in a forest-agriculture mosaic in southern Mexico. Ecology and Society 12(2):31. [online] URL: http:/ /www.ecologyandsociety.org/vol12/iss2/art31/.

Spies, T. A., W. J. Riple, and G. A. Bradshaw. 1994. Dynamics and pattern of a managed 
coniferous forest landscape in Oregon. Ecological Applications 4:555-568.

Solomon, S., D. Qin, M. Manning, R. B. Alley, T. Berntsen, N. L. Bindoff, Z. Chen, A. Chidthaisong, J. M. Gregory, G. C. Hegerl, M. Heimann, B. Hewitson, B. J. Hoskins, F. Joos, J. Jouzel, V. Kattsov, U. Lohmann, T. Matsuno, M. Molina, N. Nicholls, J. Overpeck, G. Raga, V. Ramaswamy, J. Ren, M. Rusticucci, R. Somerville, T. F. Stocker, P. Whetton, R.A. Wood, and D. Wratt. 2007. Technical summary. In S. Solomon, D. Qin, M. Manning, Z. Chen, M. Marquis, K. B. Averyt, M. Tignor, and H. L. Miller, editors. Climate change 2007: the physical science basis. Contribution of Working Group I to the Fourth Assessment Report of the Intergovernmental Panel on Climate Change. Cambridge University Press, Cambridge, UK.

Sturtevant, B. R., A. Fall, D. D. Kneeshaw, N. P. P. Simon, M. J. Papaik, K. Berninger, F. Doyon, D. G. Morgan, and C. Messier. 2007. A toolkit modeling approach for sustainable forest management planning: achieving balance between science and local needs. Ecology and Society 12 (2):7. [online] URL: http://www.ecologyandsociety.

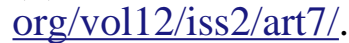

Swanson, F. J. 2004. Roles of scientists in forestry policy and management: views from the Pacific Northwest. Pages 112-126 in K. Arabas and J. Bowersox, editors. Forest futures: science, politics, and policy for the next century. Rowman and Littlefield, Lanham, Maryland, USA. 